\title{
Massive volcanic eruption seen on jovian moon
}$$
\text { 政 }
$$

Astronomers have witnessed a spectacular eruption on lo, the fiery moon of Jupiter. NASA's New Horizons probe snapped pictures (right) of a volcanic plume 350 kilometres high -40 times the height of Mount Everest - when the probe passed by Jupiter in February and March on its way to Pluto.

Results from the fly-by were presented at the annual meeting of the American Astronomical Society's Division for Planetary Sciences on 9 October in Florida, and also appear as papers in the 12 October issue of Science.

Scientists were surprised to find that Jupiter's weather was abnormally quiescent. But lo - kneaded by Jupiter's gravity into constant volcanic upheaval - didn't disappoint.

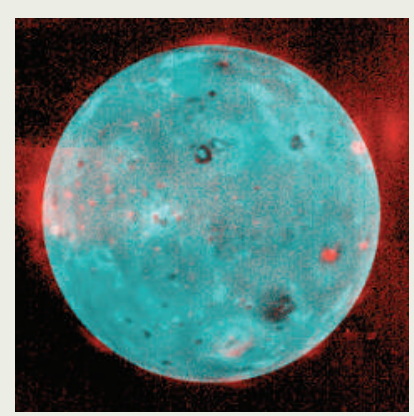

Scientists took 39 pictures of the Tvashtar volcano over 8 days, as an orange, sulphur-rich plume rocketed out at speeds up to 700 metres per second.

in authorizing the agency to carry out the census. On 4 October, US Senator Jeff Bingaman (Democrat, New Mexico) introduced a bill, the SECURE Water Act, that would expand the survey's groundwater and stream-flow monitoring programmes.

\section{Equal pay for women in science is achievable}

Aggressive academic management can correct pay disparities between male and female scientists, say researchers. Their study assesses the effects of intervention to equalize salaries at the University of Arizona's College of Medicine in Tucson between 2000 and 2004 (A. L. Wright et al. J. Gen. Intern. Med. $22,1398-1402 ; 2007)$. By 2004, women with basic science doctorates, for instance, were paid $97.6 \%$ of the amount men were paid.

Lead author Anne Wright, the college's associate dean for faculty affairs, says the study was undertaken to gauge the success of administrative actions after an earlier analysis found women faculty members were paid about \$13,000 (11\%) less than men (A. L. Wright et al. Acad. Med. 78, 500-508; 2003).

The new study directly involved personnel records of about 400 faculty members, anthropologist Wright says, rather than using a percentage of staff who respond to a survey.

\section{Cancer institute named after benefactor}

The Massachusetts Institute of Technology (MIT) in Cambridge, will replace its Center for Cancer Research with the David H. Koch Institute for Integrative Cancer Research, it announced on 9 October.

Koch, a 67-year-old businessman and MIT alumnus, is battling cancer. He has committed $\$ 100$ million to help build the facility, which should be completed in $\mathbf{2 0 1 0}$ at a cost of $\$ 280$ million. MIT bent its rules for Koch by committing to build the institute before it had the usual $80 \%$ of building costs.

\section{BEST OF NATURE}

Have you ever seen something in Nature - be it a research paper, news story or an editorial - that you thought deserved far more attention that it received? We value your opinion, so we've launched a website, 'Best of Nature', that allows readers to nominate, vote for and discuss content from Nature's past. Visit http://spotlight.nature. $\mathrm{com} /$ bestofnature and tell us what we may have missed while compiling the 'History of the Journal Nature', a newly launched website which explores Nature's history back to the very first issue in 1869. 